\title{
Ivermectin and the rule of law
}

\author{
D W Thaldar, PhD \\ School of Law, College of Law and Management Studies, University of KwaZulu-Natal, Durban, South Africa
}

Corresponding author:DWThaldar (ThaldarD@ukzn.ac.za)

\begin{abstract}
The ivermectin saga has taken on a new dimension: respect for the rule of law by the state. The rule of law is important, as it is a cornerstone of our democratic Constitutional order. The South African Health Products Regulatory Authority (SAHPRA) has a statutory mandate to regulate medicines and related substances, but it also has a constitutional duty to obey the law. This duty includes obeying court orders. However, SAHPRA appears to have contravened the consent order handed down by the Pretoria High Court on 2 February 2021, and therefore undermined the rule of law. This situation is untenable in our democratic Constitutional order.
\end{abstract}

S Afr J Bioethics Law 2021;14(2):X-X. https://doi.org/10.7196/SAJBL.2021.v14i2.763

This article is not about the merits or demerits of using ivermectin to prevent or treat COVID-19. Rather, it is about the ongoing lawsuits surrounding ivermectin, particularly about a concerning affront to the rule of law that becomes evident from the court papers filed in these lawsuits.

The rule of law is a founding value of South Africa (SA)'s democratic dispensation, ${ }^{[1]}$ and refers to the principle of governance in which all persons, including the state itself, are accountable to the law. ${ }^{[2]}$ It requires measures to ensure, inter alia, legal certainty, transparency and avoidance of arbitrariness. ${ }^{[2]}$ The rule of law is fundamental to political stability, achieving social progress, protecting human rights, curbing corruption, restraining the abuse of power and establishing the social contract between people and the state. ${ }^{[2]} \mathrm{A}$ core element of the rule of law is that the executive branch of the state must comply with court orders by the judicial branch. I elaborate on this in more detail below.

In the following, I sketch the background to the ongoing lawsuits surrounding ivermectin, and provide an overview of the litigation that has ensued and the critical events interwoven with this litigation. I then analyse these events, and highlight aspects that are cause for concern.

\section{The ivermectin saga thus far Background: COVID-19 and ivermectin}

The battle lines in the ivermectin saga were initially drawn between those who were for and those who were against allowing ivermectin to be prescribed to prevent or treat COVID-19. The opposing positions may be summarised as follows: the SA Health Products Regulatory Authority (SAHPRA) took a firm stance against ivermectin, and pointed out that, as the regulatory authority, it had not approved ivermectin for use in humans. ${ }^{[3]}$ It was firm in its stance that ivermectin is 'unproven in the management of COVID-19 infections', and warned that using ivermectin could potentially lead to harmful effects or even death. ${ }^{[3]}$ On the other side of the debate, dissatisfied medical practitioners and civil society organisations argued that in early studies, ivermectin has shown promise as a medical 'tool' to combat COVID-19, and, given that they lack such effective tools, they should be allowed to prescribe it. ${ }^{[4]}$ Additionally, they argued that the COVID-
19 pandemic constitutes a crisis, and that the normal standards for allowing a medicine to be used should be relaxed. ${ }^{[4]}$

\section{Initial litigation and the Ivermectin Controlled Compassionate Use Programme}

SAHPRA soon faced mounting public pressure and two lawsuits. ${ }^{[5,6]}$ While insisting that it did not buckle under pressure, but arrived at a new position based on its own deliberations with the scientific and medical community, ${ }^{[7]}$ SAHPRA announced the Ivermectin Controlled Compassionate Use Programme Guideline on 28 January 2021. ${ }^{[8]}$ In terms of this programme, ivermectin would not be registered as a medicine, but medical practitioners could apply to SAHPRA for permission to prescribe it for individual, named patients. ${ }^{\left[{ }^{[8]}\right.}$ The programme provided a basis upon which litigants could craft a consent order that was made an order of the court on 2 February $2021 .{ }^{[9]}$ In the court order, it was recorded that in terms of the programme: ${ }^{[9]}$

' 1.1 Ivermectin will be made available in terms of section 21 of the Medicines and Related Substances Control Act 101 of 1965;

1.2 Any person .... is eligible for access to Ivermectin in terms of the Programme;

$1.3 . .$. any registered Medical Practitioner ... [is] entitled to apply for access to Ivermectin on the terms and conditions, including the reporting obligations, specified in the Programme.'

With the court order serving as a legal endorsement of the programme, the public narrative around ivermectin in SA shifted from whether or not ivermectin should be allowed, to how the programme was to be implemented. In terms of the programme, medical practitioners' applications for permission to prescribe ivermectin had to be submitted via SAHPRA's online system, and an SMS had to be sent to SAHPRA confirming the application. ${ }^{[8]}$ Several issues of concern soon arose among medical practitioners who applied in terms of the programme. ${ }^{[4]}$ One of these issues stands out: applications that were lodged on SAHPRA's online system remained 'pending' for days on end. ${ }^{[10]}$ Given the reality of the progression of COVID-19 in a patient, one would reasonably except SAHPRA to provide feedback within minutes or at most hours, and certainly not days. One would certainly 
not expect the system to reflect applications' status as 'pending' for a seemingly indefinite period. It should be further noted that in the programme guideline document attached to the court order, SAHPRA undertook to respond to all applications within 24 hours. ${ }^{[8]}$

The situation described above raises the question: did SAHPRA comply with the court order? One should bear in mind that implementing the programme is not something that SAHPRA does at its own discretion; it is part of a court order - SAHPRA has a legal duty to implement the programme.

The ceasefire in legal hostilities between the parties was not to last for long. During February 2021, additional parties entered the fray by filing new motions against SAHPRA. ${ }^{[11,12]}$

\section{The litigation continues}

In an affidavit filed in answer to the cases brought against it, SAHPRA states that its online application system 'collapsed' from 28 January to 1 February $2021 .{ }^{[13]}$ Consequently, it lost all data submitted during this critical period just after its programme was launched. ${ }^{[14]}$ However, elsewhere in the same affidavit, the system 'malfunction' is indicated to have lasted a day longer, namely until 2 February 2021 . $^{[15]}$ SAHPRA explains the 'collapse' of its online system by stating that this system was originally created as an 'emergency' system during the early days of SAHPRA, and was not intended to handle the 'sudden abnormal increase in volume of applications as a result of the programme.[13] Despite these system limitations, SAHPRA states that the 'collapse' of its system was an 'unforeseen' problem, ${ }^{[16]}$ and that it has already commissioned a new system with enhanced stability and functionality. ${ }^{[17]}$ It states that:

'SAHPRA has adopted a continuous improvement model for reviewing the programme and improving efficiencies where this is possible. ${ }^{\text {[18] }}$

In terms of actual numbers, SAHPRA states that as of 16 February 2021, it had knowledge of 127 ivermectin applications received, with the caveat that an unknown number had been lost due to the system 'collapse. ${ }^{[13,14]}$ Of these 127 applications, 54 have been approved, 41 rejected and 32 are pending. ${ }^{[13]}$ Only 15 of the 127 applications predate the launch of the programme. ${ }^{[13]}$ SAHPRA admits that it did not meet the 24-hour response time as stated in the programme guideline (which was made part of the court order), but states that it is confident that going forward an 'expeditious turnaround time will be met.'[19]

The various cases against SAHPRA, as the main respondent, are set to be heard together in the Pretoria High Court at the end of March.

\section{Analysis \\ The malfunctioning online system}

We are all reliant on technology. Most of us know the feeling of having to deal with the frustration of a computer malfunction. In this case, a computer malfunction caused problems for SAHPRA, which had an unfortunate ripple effect on certain medical practitioners, their patients and the patients' families. However, technology itself has no moral or legal blameworthiness. SAHPRA, on its own version, knew that its online submission system was a mere 'emergency' system; also, it should reasonably have foreseen an increase in the volume of applications after announcing its programme. Using the emergency online application system was SAHPRA's own choice. It could have used emails, a cloud-based file-sharing service such as Dropbox or even old-fashioned facsimiles. A reasonable person (or reasonable organ of state) in SAHPRA's position would have ensured beforehand that whatever system it planned to use would be sufficiently robust so as not to 'collapse' at the outset. As such, SAHPRA's system malfunction is a self-inflicted wound. However, this is not my main critique.

\section{The consequences of the malfunctioning online system}

My main critique revolves around how SAHPRA handled the collapse of the online application system. SAHPRA, in its affidavit, states that it has already commissioned a new, enhanced system. ${ }^{[17]}$ Superficially, this action might seem sufficiently responsive, but seen in the broader context, it appears to be an entirely insufficient response. The Pretoria High Court granted medical practitioners the right to apply for access to ivermectin; SAHPRA, therefore, has a concomitant duty to process such applications. As pointed out previously, an indeterminate number of medical practitioners attempted to exercise this right during the 5- (or 6)-day long period of 28 January to 1 (or 2) February 2021. However, unbeknownst to them, their applications were lost and never processed by SAHPRA. However, it is clear that SAHPRA knew of the loss of these applications, and should immediately have taken steps to remedy such loss. The most obvious solution for SAHPRA would have been to use the SMS records. It should be borne in mind that SAHPRA required applicants to send an SMS to SAHPRA to confirm the submission of the online application, and thus would have had the SMS contact details of all the applicants. ${ }^{[20]}$ However, SAHPRA fails to explain why it did not use its SMS records. If the SMS records were somehow also lost, SAHPRA could have issued a public statement of apology, notifying applicants who applied during the period of 28 January to 1 (or 2) February 2021 of the need to reapply. It is unacceptable that SAHPRA kept the data loss a secret until the new wave of litigation forced it to reveal this embarrassing fact.

While the 5 (or 6)-day long online system malfunction arguably constitutes negligence on the part of SAHPRA, the authority's failure to take measures to contact the medical practitioners who applied during the malfunction period constitutes an intentional breach of the court order. In Nyathi v MEC for Health, Gauteng, the Constitutional Court per Madala J held as follows:

'Certain values in the Constitution have been designated as foundational to our democracy. This in turn means that as pillarstones of this democracy, they must be observed scrupulously. If these values are not observed and their precepts not carried out conscientiously, I have a recipe for a Constitutional crisis of great magnitude. In a state predicated on a desire to maintain the rule of law, it is imperative that one and all should be driven by a moral obligation to ensure the continued survival of our democracy. That, in my view, means at the very least that there should be strict compliance with court orders.'21

SAHPRA, as an organ of state, should set an example of respecting the rule of law - which includes strict compliance with court orders. In its press statements, SAHPRA has threatened any person who imports ivermectin with a harsh legal response. ${ }^{[3]}$ Now, given its failure to act, SAHPRA itself is in contempt of court. This not only erodes SAHPRA's moral authority and legitimacy, it also chips away at a cornerstone of our democracy, the rule of law.

While SAHPRA's handling of the 'collapse' of the online application system is the main issue, at least three other issues need to be highlighted from the perspective of the rule of law. 


\section{The basis for decision-making}

SAHPRA fails to state its criteria for approving or rejecting applications for the use of ivermectin. The programme document is also silent on this question. As can be expected, this causes frustration among medical practitioners who apply for permission to prescribe ivermectin in terms of the programme. ${ }^{[22]}$ In this context, the rule of law requires that rules made by public bodies must be clear and accessible, ${ }^{[23,24]}$ and that any exercise of public power must be rationally related to the purpose for which the power is exercised. ${ }^{[25]}$ To conform to these standards of the rule of law, SAHPRA should immediately publish objective, measurable criteria that it will use in evaluating applications for the use of ivermectin in terms of the programme.

\section{The time frame for decision-making}

SAHPRA's statement that it is confident that going forward an'expeditious' turnaround time may be expected is vague and problematic. The programme guideline, which is part of the court order, is specific: SAHPRA must respond to all applications within 24 hours. Given the context, namely patients who are sick with COVID-19, a reasonable turnaround time should be minutes, or a few hours at most. If this is compromised, the very purpose of the programme is undermined.

\section{Guarding against future data loss}

SAHPRA states that it has already commissioned a new, more stable online submission system. However, it does not explain how the new system will be more stable than the old one. The Protection of Personal Information Act No. 4 of 2013 (POPIA ${ }^{[26]}$ is relevant in this context. Although most of its substantive provisions entered into force on 1 July $2020,{ }^{[27]}$ the duty to comply is suspended for a 1-year grace period. ${ }^{[28]}$ Nevertheless, the provisions of POPIA can serve as a useful guide in the current situation. In terms of section 19 of POPIA, a person in the position of SAHPRA who 'determines the purpose of and means for processing personal information' has a legal duty to secure the integrity of personal information under its control. In particular, it must take appropriate 'reasonable technical and organisational measures' to prevent loss of personal information. In light of the data-loss debacle, it is fair to expect SAHPRA to state what 'reasonable technical and organisational measures' it has taken to avoid a repeat event.

\section{Conclusion}

The COVID-19 crisis is exposing cracks in an already strained health system in SA. It is especially in crises that adherence to the rule of law is essential. This is because crises make persons' rights more susceptible to being trampled upon by the state and its organs. SAHPRA's silence about its system malfunction, and its failure to contact the medical practitioners whose applications were lost due to the system malfunction, caused anguish for (and trampled on the legal rights of) the affected medical practitioners, their patients and the patients' families. Moreover, it constitutes non-compliance with the court order, and hence is a violation of the rule of law. The SAHPRA board should initiate a process of introspection within the regulating authority. This cannot occur again. South Africans must be able to trust their health products regulatory authority.

Editor's declaration. As a board member of SAHPRA, Prof. Ames Dhai, the editor of $S A J B L$, had no involvement in the editorial review and decisionmaking processes with regard to this article.
Acknowledgements. The author wishes to thank Stephen Peté, Adrian Bellengère and Marietjie Botes for their helpful comments on this article. All remaining errors are the author's alone.

Author contributions. Sole author.

Funding. None.

Conflicts of interest. None.

1. Constitution of the Republic of South Africa, 1996. Section 1. https://www.justice gov.za/legislation/constitution/pdf.html (accessed 4 March 2021).

2. United Nations. What is the rule of law? Geneva: UN, no date. https://www. un.org/ruleoflaw/what-is-the-rule-of-law/ (accessed 4 March 2021).

3. South African Health Products Regulatory Authority. Media release: Ivermectin is not indicated nor approved by SAHPRA for use in humans. Pretoria: SAHPRA 22 December 2020. https://www.sahpra.org.za/wp-content/uploads/2020/12/ Media-release-Ivermectin.pdf (accessed 4 March 2021).

4. 'I can make a difference' doctors and medical practitioners group v SAHPRA. $6391 / 2021$ ZAHCGP. Founding affidavit.

5. Coetzee v SAHPRA. 2820/2021 ZAHCGP.

6. ACDP v SAHPRA. $3792 / 2021$ ZAHCGP.

7. South African Health Products Regulatory Authority. SAHPRA clarifies its stance on ivermectin. Pretoria: SAHPRA, 3 February 2021. https://www.sahpra.org.za/ press-releases/sahpra-clarifies-its-stance-on-ivermectin/ (accessed 4 March 2021).

8. South African Health Products Regulatory Authority. Ivermectin Controlled Compassionate Use Programme Guideline. Pretoria: SAHPRA, 28 January 2021. https://www.sahpra.org.za/wp-content/uploads/2021/01/Section_21 Ivermectin_Controlled_Compassionate-Use-Programme_Jan21_FINAL.docx.pdf (accessed 4 March 2021).

9. Coetzee v SAHPRA. 2820/2021 ZAHCGP. Order. 2 February 2021. https:// www.sahpra.org.za/wp-content/uploads/2021/02/COURT-ORDERGRANTED-2021-02-03.pdf (accessed 4 March 2021).

10. 'I can make a difference' doctors and medical practitioners group v SAHPRA. 6391/2021 ZAHCGP. Founding affidavit paras 89-101.

11. 'I can make a difference' doctors and medical practitioners group $\vee$ SAHPRA. 6391/2021 ZAHCGP.

12. Pharma Valu CC v SAHPRA. $9086 / 2021$ ZAHCGP.

13. 'I can make a difference' doctors and medical practitioners group $\vee$ SAHPRA. 6391/2021 ZAHCGP. Answering affidavit para 81.

14. 'I can make a difference' doctors and medical practitioners group $\vee$ SAHPRA. 6391/2021 ZAHCGP. Answering affidavit para 84.

15. 'I can make a difference' doctors and medical practitioners group $\vee$ SAHPRA. 6391/2021 ZAHCGP. Answering affidavit para 228.

16. 'I can make a difference' doctors and medical practitioners group v SAHPRA. 6391/2021 ZAHCGP. Answering affidavit para 88.

17. 'I can make a difference' doctors and medical practitioners group $\vee$ SAHPRA. 6391/2021 ZAHCGP. Answering affidavit para 84.3.

18. 'I can make a difference' doctors and medical practitioners group $\vee$ SAHPRA. 6391/2021 ZAHCGP. Answering affidavit para 222.

19. 'I can make a difference' doctors and medical practitioners group $v$ SAHPRA. 6391/2021 ZAHCGP. Answering affidavit para 230.

20. 'I can make a difference' doctors and medical practitioners group v SAHPRA. 6391/2021 ZAHCGP. Replying affidavit para 132.

21. Nyathi v MEC for Health, Gauteng 2008 (5) SA 94 (CC) para 80.

22. 'I can make a difference' doctors and medical practitioners group $\vee$ SAHPRA. 6391/2021 ZAHCGP. Replying affidavit paras 5.1.3 and 83.

23. Dawood v Minister of Home Affairs 2000 (3) SA 936 (CC) para 47.

24. Affordable Medicines Trust v Minister of Health 2006 (3) SA 247 (CC) para 108.

25. Pharmaceutical Manufacturers Association of South Africa: In re Ex Parte President of the Republic of South Africa 2000 (2) SA 674 (CC) para 85.

26. South Africa. Protection of Personal Information Act No. 4 of 2013. https://www. gov.za/sites/default/files/gcis_document/201409/3706726-11act4of2013protec tionofpersonalinforcorrect.pdf (accessed 4 March 2021).

27. South Africa. Proclamation R21 of 2020. Commencement of certain sections of the Protection of Personal Information Act No. 4 of 2013, GG 43461 of 22 June 2020. https://www.gov.za/sites/default/files/gcis_document/202006/43461 rg11 136pr21.pdf (accessed 4 March 2021).

28. South Africa. Protection of Personal Information Act 4 of 2013. Section 114(1). https://www.gov.za/sites/default/files/gcis_document/201409/370672611 act4of2013protectionofpersonalinforcorrect.pdf (accessed 4 March 2021).

Accepted 15 March 2021. 